\title{
Brain SCALE: Brain Structure and Cognition: an Adolescent Longitudinal Twin Study into the Genetic Etiology of Individual Differences
}

\author{
Inge L. C. van Soelen, ${ }^{1,2}$ Rachel M. Brouwer, ${ }^{2}$ Jiska S. Peper, ${ }^{2,3}$ Marieke van Leeuwen, ${ }^{1,4}$ Marinka M. G. \\ Koenis, ${ }^{2}$ Toos C. E. M. van Beijsterveldt, ${ }^{1}$ Suzanne C. Swagerman, ${ }^{1}$ René S. Kahn, ${ }^{2}$ Hilleke E. Hulshoff \\ Pol, $^{2}$ and Dorret I. Boomsma ${ }^{1}$ \\ ${ }^{1}$ Department of Biological Psychology, VU University, Amsterdam, The Netherlands. \\ ${ }^{2}$ Rudolf Magnus Institute of Neuroscience, Department of Psychiatry, University Medical Center, Utrecht, The Netherlands. \\ ${ }^{3}$ Institute of Psychology, Brain and Development Laboratory, Leiden University, The Netherlands. \\ ${ }^{4}$ Department of Psychosocial Research and Epidemiology, The Netherlands Cancer Institute, Amsterdam, The Netherlands.
}

\begin{abstract}
From childhood into adolescence, the child's brain undergoes considerable changes in both structure and function. Twin studies are of great value to explore to what extent genetic and environmental factors explain individual differences in brain development and cognition. In The Netherlands, we initiated a longitudinal study in which twins, their siblings and their parents are assessed at three year intervals. The participants were recruited from The Netherlands Twin Register (NTR) and at baseline consisted of 112 families, with 9-year-old twins and an older sibling. Three years later, 89 families returned for follow-up assessment. Data collection included psychometric IO tests, a comprehensive neuropsychological testing protocol, and parental and self-ratings of behavioral and emotional problems. Physical maturation was measured through assessment of Tanner stages. Hormonal levels (cortisol, luteinizing hormone, follicle-stimulating hormone, testosterone, and estrogens) were assessed in urine and saliva. Brain scans were acquired using 1.5 Tesla Magnetic Resonance Imaging (MRI), which provided volumetric measures and measures of cortical thickness. Buccal swabs were collected for DNA isolation for future candidate gene and genomewide analysis studies. This article gives an overview of the study and the main findings. Participants will return for a third assessment when the twins are around 16 years old. Longitudinal twin-sibling studies that map brain development and cognitive function at well-defined ages aid in the understanding of genetic influences on normative brain development.
\end{abstract}

Keywords: twin study, development, MRI, growth, puberty, IQ

Some decades ago, the brain of an adolescent was considered to be comparable to an adult brain. This view has been revised, largely due to the development of non-invasive neuroimaging techniques, in particular MRI. These techniques have initiated a new field of research on the neurobiology of the adolescent brain. Gaining insight into the maturational processes that take place during this period of brain development, and into the etiology of individual differences in these processes, will aid in understanding the development of psychiatric disorders, since many psychiatric disorders become apparent around or right after puberty (Kessler et al., 2007; Paus et al., 2008).

The transition from childhood to adolescence is characterized by cognitive maturation (Casey et al., 2005b; Keating, 2004; Steinberg, 2005; Crone, 2009). Children improve considerably in specific cognitive functions, including in- formation processing (Demetriou et al., 2002), working memory (Gathercole et al., 2004), and verbal learning (van den Burg \& Kingma, 1999). During adolescence, complex, non-linear, and region-specific structural changes occur in the human brain. White matter (WM) tissue shows an

RECEIVED 9 November 2011; ACCEPTED 14 December 2011.

ADDRESS FOR CORRESPONDENCE: Dorret Boomsma, Department of Biological Psychology, VU University, Van der Boechorststraat 1, 1081 BT, Amsterdam, The Netherlands. E-mail: di.boomsma@vu.nl OR Hilleke Hulshoff Pol, Department of Psychiatry, A01.126, University Medical Center, Utrecht, Heidelberglaan 100, 3584 CX Utrecht, The Netherlands. E-mail: h.e.hulshoff@umcutrecht.nl 
almost linear increase in volume with age, and continues to increase in adults until approximately 45 years (Bartzokis et al., 2001; Lebel \& Beaulieu, 2011), while gray matter (GM) tissue initially increases in volume in childhood and, after peaking around puberty, starts to decrease (Giedd et al., 2006; Paus, 2005). This decrease in GM volume is most often associated with overall thinning of the cortex (Gogtay et al., 2004; Sowell et al., 2002). In general, GM cortical changes occur first in primary cortical areas (e.g., sensory-motor cortex), followed by secondary and multimodal cortical areas throughout childhood and adolescence (Gogtay et al., 2004; Sowell et al., 2002). The biological processes underlying these structural changes in GM and WM around puberty are incompletely understood. One of the hypotheses for GM loss is the process of synaptic pruning (Huttenlocher \& Dabholkar, 1997). Decrease in GM, and increase in WM, are also thought to be a reflection of progressive, age-related axonal myelination (Benes et al., 1994; Yakovlev \& Lecours, 1967).

The development of psychopathology and psychiatric disorders might be influenced, or may even be initiated, by processes influencing development of the brain (Insel, 2010; Karmiloff-Smith, 2010; Shaw et al., 2010). Integrating the tools of genomics and neuroscience may reveal causes of neuropsychiatric illnesses, and suggest new strategies for treatment and prevention (Akil et al., 2011). Nearly all psychiatric disorders have a genetic origin, whether they originate in childhood (e.g., Faraone et al., 2005; Muhle et al., 2004), or in adolescence/adulthood (e.g., Bienvenu et al., 2011). To understand disrupted brain development, it is vital to understand normal or healthy brain development (Luna \& Sweeney, 2001), and how healthy brain development is influenced by genotype and environmental exposures. For this purpose, twin studies are of great value to explore to what extent genetic and environmental factors explain individual differences in brain development and cognition.

The longitudinal twin study described in this paper aims to examine how genetic and environmental influences affect individual differences in developmental changes in brain structure and cognition during the transition from childhood to adolescence. A population-based study of a cohort of twins and their siblings was started in 2005. At baseline, 9-year-old twins and an older sibling were included in a study of brain development and cognition. Their parents also took part in cognitive testing. Around the 12th birthday of the twins, the families were invited for follow-up and a third assessment is currently scheduled. In this paper, we present an overview of data acquisition, a characterization of the participants, and a summary of the main results so far. This is followed by a discussion on how these results should be viewed in the light of current knowledge on healthy brain development, and what their possible implications are for further developmental studies in health and psychopathology.

\section{Cohort Description and Testing Procedures \\ Participants}

All twin families were recruited from The Netherlands Twin Registry (NTR) (Boomsma et al., 2006). Families from birth cohorts 1995-1996 were selected based on zygosity of the twins, and whether they had an older brother or sister aged less than 14 years. This age limit for siblings was set to optimize future comparisons with the twin data. Exclusion criteria were: having a pacemaker; metal materials in the head (except for dental braces); chronic use of medication; a known major medical or psychiatric history; participation in special education; and physical or sensory disabilities. In total, 214 families were invited by letter, which also included information brochures for parents and children. Two weeks later they were contacted by phone and 112 families agreed to take part in the study. In this group, 103 twin pairs had a full sibling who met inclusion criteria and was willing to participate. The most common reasons for refusal were: no time or too much effort $(n=52)$; children did not want to participate or were scared $(n=13)$; parents did not want their children to participate $(n=10)$; and problems with children, like hospitalization, psychiatric problems of which we were not aware, and divorce of parents $(n=9)$. Data acquisition was randomized across time with respect to sex and zygosity of twins. At baseline, mean age of the twins was 9.2 years $(S D=0.5$, range 8.9-9.6). Zygosity of the samesex twins was determined by DNA polymorphisms. There were 48 monozygotic (MZ) pairs ( 23 male/25 female), 44 same-sex dizygotic (DZ) pairs (23 male/21 female), and 20 dizygotic pairs of opposite sex. Mean age of siblings $(N=$ 105 , 59 female) was 11.9 years (range $=9.9-14.9$ ). Mean age of fathers was 43.9 years $(S D=4.2)$, and of mothers 41.8 years $(S D=3.3)$. Table 1 provides more details on the participants, including handedness and IQ. IQ scores were somewhat higher in sibs than in twins. In a larger project (de Zeeuw et al., 2012), we found that this difference is explained

\section{TABLE 1}

Number of Participants, Age, IQ, and Handedness at Baseline and Follow-up

\begin{tabular}{lcc}
\hline & Baseline & Follow-up \\
\hline Twins & & \\
Total number of twins (male/female) & $224(112 / 112)$ & $178(89 / 89)$ \\
MZ/same-sex DZ/opposite sex DZ & $48 / 44 / 20$ & $40 / 34 / 15$ \\
$\quad$ twin pairs & & \\
Mean age of twins in years (SD) & $9.2(.1)$ & $12.1(.3)$ \\
Mean IQ score (SD) & $99.9(13.5)$ & $100.3(14.1)$ \\
Handedness (right/non-right) & $184 / 34^{\mathrm{a}}$ & $149 / 29$ \\
Siblings & & \\
Total number of siblings & $105(46 / 59)$ & $82(37 / 45)$ \\
$\quad$ (male/female) & $11.9(1.1)$ & $14.8(1.3)$ \\
Mean age of siblings in years (SD) & $106.3(16.3)$ & $105.0(17.5)$ \\
Mean IQ score (SD) & $93 / 9^{a}$ & $75 / 7$ \\
Handedness (right/non-right) &
\end{tabular}

Note: $\mathrm{MZ}=$ monozygous, $\mathrm{DZ}=$ dizygous

${ }^{a}$ Data on handedness are missing for 6 twins and 3 siblings at baseline. 


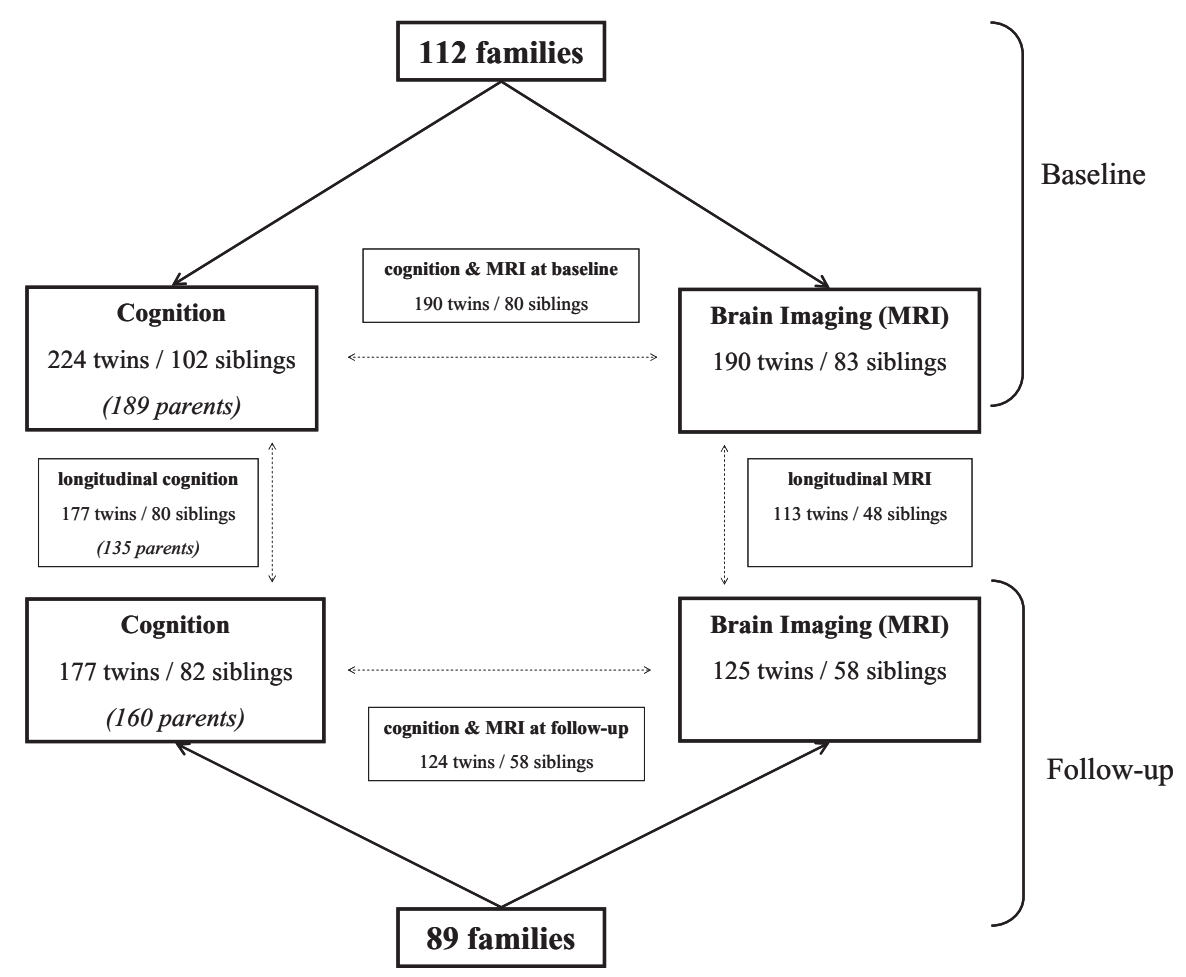

\section{FIGURE 1}

Data collection at baseline and at follow-up for cognitive functioning (number of psychometric $1 \mathrm{Q}$ tests for twins and siblings, and Raven Advanced Progressive matrices for parents) and brain structure (number of MRI scans after image processing).

by birth order, with older sibs in the family having a higher IQ.

When the twins reached the age of 12 , the families were contacted by letter and phone. Eighty-nine families agreed to participate at the follow-up, resulting in a response rate of approximately $80 \%$. In the 23 families that did not return, the most important reasons for non-participation were no time, too much effort $(n=8)$; some or all family members did not want to participate $(n=11)$; moved to another country $(n=2)$; and families who moved and new contact details could not be retrieved in time $(n=2)$. Mean age of twins at follow-up was 12.2 years $(S D=0.3$, range $=11.7-$ 13.1). The follow-up group comprised $40 \mathrm{MZ}$ (20 male/20 female), $34 \mathrm{DZ}$ (17 male/17 female), and 15 opposite-sex DZ pairs. Mean age of the siblings $(N=82 ; 45$ female) was 14.8 years $(S D=1.3$, range $9.8-18.0$, one younger sibling was included) (see also Table 1).

The study was approved by the Central Committee on Research Involving Human Subjects of The Netherlands (CCMO), and studies were performed in accordance with the Declaration of Helsinki. Parents signed informed consent forms for the children and for themselves. Parents were financially compensated for travel expenses, and children received a present or gift voucher at the end of the testing days. In addition, a summary of cognition scores and a printed image of their MRI scan, when available, were provided afterwards.

\section{Procedures}

At baseline the data were collected on two separate days. On one day children were tested at the VU University (VU) in Amsterdam (neuropsychological testing and sample collection of urine and saliva), and on the other day at the University Medical Center in Utrecht (UMCU; MRI scan acquisition). Average time between cognitive testing and MRI scan was 50 days (range $=4-128$ ). At follow-up, all data were collected at the same day at the UMCU. An overview of the available scans and cognitive data is illustrated in Figure 1.

\section{Neuropsychological Tests}

Data on cognitive abilities were collected with psychometric IQ and neuropsychological tests. A small number of tests that exhibited low reliability and/or limited genetic influences at baseline were not repeated at follow-up: Tower of Hanoi (Simon, 1975), Eriksen flanker task (Eriksen \& Eriksen, 1974; Eriksen \& Schultz, 1979), and the 'Reading the Mind in the Eyes' task (Baron-Cohen et al., 2001). The description of the neuropsychological tests in the section below includes the tests collected at both baseline and follow-up.

The main phenotypic outcome measures of the cognitive tests, hormonal levels, puberty stage, height, and weight are given in Table 2 for twins and siblings. All children were tested by a series of subtests from the Wechsler Intelligence 
TABLE 2

Mean Scores for Main Variables Collected at Baseline and Follow-up for Twins and Their Siblings

\begin{tabular}{|c|c|c|c|c|c|c|c|}
\hline \multirow[b]{2}{*}{ Task or measure } & \multirow[b]{2}{*}{ Main output phenotype } & \multicolumn{3}{|c|}{ Baseline } & \multicolumn{3}{|c|}{ Follow-up } \\
\hline & & $\begin{array}{l}\text { Mean (SD) } \\
\text { twins }\end{array}$ & $\begin{array}{l}\text { Mean (SD) } \\
\text { siblings }\end{array}$ & $\begin{array}{l}N \text { total } \\
\text { (twins/ } \\
\text { siblings) }\end{array}$ & $\begin{array}{l}\text { Mean }(S D) \\
\text { twins }\end{array}$ & $\begin{array}{l}\text { Mean }(S D) \\
\text { siblings }\end{array}$ & $\begin{array}{l}N \text { total } \\
\text { (twins/ } \\
\text { siblings) }\end{array}$ \\
\hline \multicolumn{8}{|l|}{ Cognition } \\
\hline Intelligence (WISC-III) & Intelligence Quotient (IQ) & $99.9(13.5)$ & $106.3(16.3)$ & $224 / 102$ & $100.5(14.2)$ & $104.7(17.5)$ & $178 / 81$ \\
\hline Raven & Number of correct answers & $36.6(7.9)$ & $45.4(7.2)$ & $224 / 103$ & $47.0(5.5)$ & $50.8(5.8)$ & $179 / 81$ \\
\hline \multirow{2}{*}{ Working memory (N-back) } & Correct answers $(N=2)$ & $28.4(10.4)$ & $38.4(13.1)$ & $217 / 99$ & $46.1(12.4)$ & $52.2(11.1)$ & $165 / 77$ \\
\hline & Correct answers $(N=3)$ & $25.5(7.9)$ & $32.6(8.9)$ & $213 / 98$ & $35.9(11.2)$ & $42.7(12.2)$ & $161 / 75$ \\
\hline Inhibition (Stroop) & Interference time (s) & $71.7(26.5)$ & $48.6(17.3)$ & 213/101 & $43.7(17.8)$ & $34.5(19.3)$ & $177 / 80$ \\
\hline Spatial memory (Corsi) & Number of correct trials & $12.0(3.4)$ & $15.6(3.8)$ & $221 / 101$ & $16.9(4.0)$ & $19.0(3.7)$ & $173 / 79$ \\
\hline \multirow{2}{*}{ Verbal fluency } & Number Letter & $12.2(3.9)$ & $16.3(4.8)$ & $224 / 102$ & $17.0(4.9)$ & $20.5(6.3)$ & $179 / 81$ \\
\hline & Number Category & $22.2(5.0)$ & $28.6(5.7)$ & $224 / 102$ & $29.6(5.9)$ & 34.7 (7.2) & $178 / 81$ \\
\hline \multirow[t]{2}{*}{ Verbal learning (AVLT) } & Total correct after 5 trials & $39.9(8.2)$ & $48.0(7.0)$ & $224 / 101$ & $49.4(7.6)$ & $54.1(8.0)$ & $163 / 75$ \\
\hline & Total correct after delay & $8.4(2.6)$ & $10.3(2.5)$ & $224 / 101$ & $10.4(2.4)$ & $11.0(2.5)$ & $160 / 74$ \\
\hline Processing speed & pi-task (number of trials) & $93.2(6.1)$ & $91.5(8.6)$ & $224 / 101$ & 90. (8.1) & $88.5(9.2)$ & $148 / 63$ \\
\hline Reading ability (1 $\mathrm{min})$ & Number of correct words & $56.9(19.6)$ & 84.7 (16.3) & $209 / 85$ & $85.2(18.0)$ & $95.0(15.8)$ & $167 / 76$ \\
\hline \multicolumn{8}{|l|}{ Physical examination } \\
\hline \multirow[t]{3}{*}{ Body } & Height $(\mathrm{cm})$ & $138.8(5.3)$ & $155.2(9.2)$ & 218/99 & $152.5(7.4)$ & $165.9(8.8)$ & $174 / 78$ \\
\hline & Weight (kg) & $31.4(4.5)$ & $44.1(9.9)$ & $218 / 99$ & 43.7 (7.9) & $57.5(9.4)$ & $174 / 78$ \\
\hline & Body Mass Index & $16.2(1.7)$ & $18.1(2.6)$ & $218 / 99$ & $18.7(2.5)$ & $20.8(2.4)$ & $174 / 78$ \\
\hline \multirow{4}{*}{ Puberty stage (Tanner) } & Penis development (boys) & $1.11(0.44)$ & $1.70(0.88)$ & $108 / 44$ & $2.13(0.85)$ & $3.68(0.98)$ & $83 / 31$ \\
\hline & Pubic hair (boys) & $1.09(0.29)$ & $1.77(0.99)$ & $107 / 44$ & $2.14(0.93)$ & $3.74(1.0)$ & $84 / 31$ \\
\hline & Breast development (girls) & $1.18(0.39)$ & $2.83(0.99)$ & $109 / 54$ & $2.94(1.1)$ & $4.23(0.87)$ & $86 / 43$ \\
\hline & Pubic hair (girls) & $1.16(0.37)$ & $2.83(1.3)$ & $108 / 53$ & $2.78(1.3)$ & $4.36(0.87)$ & $80 / 44$ \\
\hline \multicolumn{8}{|l|}{ Hormones $^{a}$} \\
\hline \multirow[t]{3}{*}{ Morning urine } & LH (U/mmol creatinine) & $0.03(0.04)$ & $0.20(0.20)$ & $113 / 89$ & $0.19(0.18)$ & $0.27(0.21)$ & $175 / 76$ \\
\hline & $\mathrm{FSH}(\mathrm{U} / \mathrm{mmol}$ creatinine $)$ & $0.36(0.25)$ & $0.68(0.49)$ & $223 / 101$ & $0.68(0.44)$ & $0.78(0.46)$ & $177 / 77$ \\
\hline & Estrogen (pmol/mmol creatinine) & $121.3(101.4)$ & $196.1(166.0)$ & $221 / 98$ & $285.3(236.6)$ & $401.2(295.0)$ & $177 / 77$ \\
\hline Saliva & Testosterone (pmol/L) & $28.3(25.1)$ & $64.9(62.8)$ & $215 / 99$ & $68.6(74.7)$ & $157.0(157.5)$ & $175 / 79$ \\
\hline \multicolumn{8}{|l|}{ Questionnaires } \\
\hline \multirow{3}{*}{$\begin{array}{l}\text { Child Behaviour Checklist } \\
\text { (CBCL) }\end{array}$} & Age (years) at moment of surveyb & $10.1(0.4)$ & $12.1(1.2)$ & $158 / 92$ & $12.2(0.3)$ & $14.7(1.3)$ & $198 / 81$ \\
\hline & Internalizing behaviour & $4.5(5.0)$ & $4.9(4.8)$ & $157 / 89$ & $4.0(5.3)$ & $4.1(5.5)$ & $196 / 80$ \\
\hline & Externalizing behaviour & $6.7(6.6)$ & $6.2(6.8)$ & $157 / 90$ & $5.3(5.6)$ & $4.4(5.2)$ & $196 / 81$ \\
\hline \multirow[t]{3}{*}{ Youth Self Report (YSR) } & Age (years) at moment of survey & - & - & $-1-$ & $12.1(0.3)$ & $14.8(1.2)$ & $175 / 81$ \\
\hline & Internalizing behaviour & - & - & $-1-$ & $8.5(6.7)$ & $8.4(7.1)$ & $172 / 80$ \\
\hline & Externalizing behaviour & - & - & $-1-$ & $8.6(5.7)$ & $8.4(6.0)$ & $174 / 81$ \\
\hline
\end{tabular}

Note: $S D=$ standard deviation, $\mathrm{LH}=$ lutenizing hormone, $\mathrm{FSH}=$ follicle stimulating hormone

${ }^{a}$ At baseline, none of the female twins reported menarche, 14 siblings reported menarche ( 5 reported a regular menstrual cycle), and none were using oral contraceptives; at follow-up, 21 reported menarche, (3 reported a regular menstrual cycle), and none used oral conceptives, 38 siblings reported menarche (32 girls reported a regular menstrual cycle, 6 used oral contraceptives).

${ }^{b}$ At baseline, collection of questionnaires was at different moments for twins and siblings. The mean scores on internalizing and externalizing behaviour of twins are based on a mailed survey, and for siblings the scores are based on questionnaires filled in around the date of lab visit.

c YSR was not collected at baseline.

Scale for Children - Third version (WISC-III) (Wechsler et al., 2002; see van Soelen et al., 2011c for more details), and the Raven Standard Progressive matrixes (Raven, 1960; van Leeuwen et al., 2008) at baseline and follow-up. Additionally, the Raven Advanced Progressive Matrices (Raven et al., 1998) were completed by the parents of twins (van Leeuwen et al., 2008). To assess working memory, children performed a spatial variant of the N-back task (Gevins \& Cutillo, 1993; Jansma et al., 2000) that was adapted to make it more appealing for young participants, and with increasing levels of difficulty (van Leeuwen et al., 2007). Both short-term and long-term memory were assessed, using the Dutch version of the Rey's Auditory Verbal Learning Test (AVLT; 15-words task) (van den Burg \& Kingma, 1999), and the Corsi block-tapping task (Corsi, 1974). Details on these memory paradigms can be found in van Leeuwen et al. (2009b) and van Soelen et al. (2009). Speed of processing was assessed with the $\pi$-inspection task (Luciano et al., 2001; van Leeuwen et al., 2007). Selective attention was assessed by the Stroop colour-word task (Stroop, 1935). The Controlled Oral Word Association task (COWA), a subtest of the Multilingual Aphasia Exam, was used to measure verbal fluency. Reading ability was assessed by asking the children to read out loud as many words as possible from a card in one minute, which consisted of a maximum of 120 words (van Leeuwen et al., 2009c). This list of words was adapted from the so-called Three Minutes Reading Task, which is frequently used in The Netherlands educational system (Cito, 1995). Handedness was determined based on the Edinburgh Handedness Inventory (Oldfield, 1971).

\section{Behavioral Data}

All parents of young twin pairs registered at the NTR receive survey questionnaires that are mailed at birth, and at ages $1,2,3,5,7,9$, and 12 years. From age 7 onwards, teachers of twins are also approached. Surveys include the Child 
Behavior Checklist (CBCL), the Teacher's Report Form (TRF), and questions about growth, health, developmental milestone, demographics, lifestyle, and school performance (Bartels et al., 2007; Bartels et al., 2009; Boomsma et al., 2005; Brouwer et al., 2006; Estourgie-van Burk et al., 2010; Felsenfeld et al., 2010; Franic et al., 2010; van Beijsterveldt \& Boomsma, 2007). The CBCL, which is completed by both parents, contains scales to assess behavioral and emotional problems in children (Achenbach, 1991). At baseline and follow-up, mothers completed the CBCL for siblings. At follow-up, twins and their siblings were asked to fill out the Dutch Health and Behavior Questionnaire (DHBQ), which includes the Youth Self Report (Achenbach \& Rescorla; 2001 Verhulst et al., 1997), to assess problem behavior, self esteem, life events, religiosity, happiness, life satisfaction, family situation, and family functioning (Bartels et al., 2007). The DBHQ was mailed to the twins and siblings before their visit to the lab, so they could complete it at home.

\section{Physical Examination}

Pubertal stage was determined by a trained project supervisor on the basis of secondary sexual characteristics (Marshall \& Tanner, 1969; Marshall \& Tanner, 1970). Tanner stages are classified on a 5-item scale (stage 1 represents no pubertal development and stage 5 represents full maturation). If children were not comfortable with this assessment by the project supervisor, they were given a choice to point out their status based on black and white photographs of the different puberty stages, which were accompanied by oral explanation by the researcher. Body weight and height were assessed for each child, and girls were asked about menarche, regularity of their menstrual cycle, and the use of oral contraceptives.

\section{Sample Collection for Hormone Assessment}

In the week before the laboratory visit, children collected samples of saliva and morning urine. Samples were stored in the refrigerator at home. All samples were handed in on arrival at the laboratory and were stored in a freezer. Hormone levels were determined in saliva (cortisol and testosterone) and urine (estradiol, luteinizing hormone and follicle-stimulating hormone). Multiple assessments at a consistent time of the day are required to decrease the influence of fluctuations in hormonal levels, particularly in children (Riad-Fahmy et al., 1987; Read et al., 1990; Walker et al., 1990). Therefore, children were instructed to collect all the samples on two school days, and to restrict the awakening time and time of sampling, because in The Netherlands the starting time of primary school is approximately similar throughout the country. Participants were asked to write down the exact sample time in a time schedule, and to note any exceptional events interfering with normal daily routine. Additionally, children were asked to collect saliva at five time points during the morning for cortisol level determination (previously described by Bartels et al., 2003).

\section{Buccal Cell Collection}

Both parents and children collected buccal swabs for DNA isolation. Subjects were asked to take 2 series of swabs on 2 days, by rubbing cotton buds along the inside of the mouth. DNA was used to determine zygosity and will be used for genome-wide association (GWA) studies in the future. Zygosity was initially determined by a set of eight highly polymorphic di-, tri-, and tetra-nucleotide genetic markers, and confirmed by additional single nucleotide polymorphism (SNP) genotyping of 64 SNPs.

\section{MRI Scan Protocol}

Scanning and image processing took place at the UMCU. All children were initially offered a practice session in a dummy scanner to become familiarized with the scan procedure, small space, and the sounds of the MRI machine (Durston et al., 2009). Exclusion criteria for the MRI scanner were any metal in or around the body that could interfere with the MRI scanner (e.g., metal braces).

For both measurements, whole head MRI scan was acquired with a 1.5 Tesla Philips Achieva scanner (Philips, Best, The Netherlands). For both baseline and follow-up, the same scan sequence parameters were applied to limit possible differences in scan acquisition. The scanning protocol included T1-weighted Magnetization Transfer Imaging (MTI) and Diffusion Tensor Imaging (DTI) scans. At follow-up, the scanning protocol was extended with a T2weighted image and a resting-state functional MRI (fMRI) scan (for more details, see Brouwer et al., 2010; Peper et al., 2008; van Soelen et al., 2011a). Children were allowed to watch a movie or listen to music during the scans, except that, during the resting-state fMRI scan, the children were asked to close their eyes and try to avoid thinking of anything in particular. The total scan protocol took approximately 45-50 minutes for each child.

\section{Future Follow-up}

Participants will be invited for a third visit when the twins are 16 years old. Cognitive assessment will include several new computerized tasks and some earlier tests will be replaced by computerized versions. The Computerized Neuropsychological Testing System (WebCNP) developed by the University of Pennsylvania (Gur et al., 2001; Gur et al., 2010) will be added to the protocol. The CNP consists of a set of cognitive tasks that take approximately one hour to administer. It provides measures of speed and accuracy on 10 neurocognitive domains. The subtests show good reliability and construct validity. In addition, they meet the criteria on which the tasks in the first two cognitive assessments were selected: they measure heritable traits, and have been linked to specific brain systems in functional neuroimaging studies. IQ will be assessed by the shortened four-test version 
of the Wechsler Adult Intelligence Scale (WAIS), namely the Wechsler Abbreviated Scale of Intelligence (WASI), including the vocabulary, similarities, matrix reasoning, and block design subtests. The Corsi block-tapping task and the Three Minutes Reading List will remain part of the cognitive assessment, and the scan protocol and scan parameters remain as previous described. New additions to the experimental protocol are the computerized Bechara's gambling task (van Leijenhorst et al., 2010), an autism questionnaire (Hoekstra et al., 2008), and blood pressure measurements.

\section{Main Findings}

An overview of main findings is presented in Table 3. Considering the focus of this special issue, we will limit our summary of results to the imaging-related publications that have resulted from this cohort. At age 9 , variability in brain volumes was highly heritable (e.g. $>90 \%$ of the variability in total brain volume) (Peper et al., 2009c). We explored GM and WM density with voxel-based morphometry (VBM). Variation in density of posterior WM, as well as of anterior (pre-)frontal and temporal GM areas, was primarily influenced by genes (Peper et al., 2009c). At follow-up, heritability estimates of global brain volume were still very high (van Soelen et al., 2011a). For all brain volumes, high genetic correlations with age were observed, indicating that individual variation in these brain volumes at the ages of 9 and 12 years were explained by the same genetic factors (van Soelen et al., 2011a). Our findings of high heritability estimates in childhood are in line with other studies reporting relatively high estimates for brain volumes during childhood and adolescence (Schmitt et al., 2007; Wallace et al., 2006; Yoon et al., 2010).

We also estimated the heritability of WM microstructure at age 9, through DTI and MTI (Brouwer et al., 2010). DTI provides information about the directionality, or so-called fiber integrity, of the underlying WM fiber bundles. MTI can be used to compute the magnetization transfer ratio (MTR), which can be seen as a measure of the amount of macromolecules in tissue, including myelin. Modest influences of genetic factors were found on diffusion parameters (longitudinal, 33-46\%, radial diffusivity, 27-64\%). Heritability estimates of the MTR signal ranged from $31-61 \%$ and were largest in the posterior part of the brain (Brouwer et al., 2010).

Between age 9 and 12 years, total brain volume increased, on average, by $14.6 \mathrm{ml}$ (van Soelen et al., 2011a), which is an increase of $1.1 \%$. The most pronounced volumetric change was observed for the cerebellum (increase of 4.2\%). Cerebral GM volume was the only volumetric measure that showed a decrease between 9 and 12 years of age (decrease of 1.6\%; see Figure 2). These volumetric changes are in line with previously reported volumetric changes based on pediatric samples, including large age ranges from young childhood up to young adulthood (e.g., Giedd et al., 1999).
The relatively large increase in cerebellar volume observed between age 9 and 12 is consistent with previous findings that the cerebellum is maturing at a later age than the cerebrum (Lenroot et al., 2007; Tiemeier et al., 2010). It can also be speculated that, in this sample, the relatively large increase in cerebellar volume that was found at age 9 is partly the result of compensating for the effect of preterm birth. Shorter pregnancy duration was found to be associated with a relatively smaller cerebellar volume at age 9 . The cerebellum is under rapid development in the last trimester of the pregnancy (Limperopoulos et al., 2005), and therefore the development of this structure in postnatal life might be particularly vulnerable to preterm birth as observed in this cohort (van Soelen et al., 2010).

Individual differences in volumetric brain changes were partly under genetic control (change in cerebral volume was $20 \%$ heritable and change in cerebellar volume $45 \%$ ). The association between changes in cerebellar and cerebral volumes $\left(r_{\mathrm{p}}=.49\right)$ was driven by shared genetic influences and, to a smaller extent, by shared unique environmental influences. As children undergo a growth spurt during puberty (Tanner \& Whitehouse, 1976), increase in height was included in bivariate genetic analyses. We observed an increase in height of $13.8 \mathrm{~cm}$ (van Soelen et al., 2011a), which was highly heritable $(73 \%)$, but was influenced by genetic factors other than those implicated in changes in cerebral volume. The modest correlation between height and cerebellar growth $\left(r_{\mathrm{p}}=.24\right)$, could be attributed partly to shared genetic influences $\left(r_{\mathrm{g}}=.48\right)$.

We conclude that developmental brain changes are evident in this 3-year interval, and that these changes are heritable. Furthermore, these changes in cerebral volume and the increase in height do not stem from the same genetic origin, while the change in cerebellar volume is partly (genetically) correlated with changes in height.

\section{Brain Structure and Puberty}

It has been assumed that puberty-related increases in sex steroids are linked to brain development (Giedd et al., 2006), but a direct association has only recently been examined (e.g., Bramen et al., 2011; Herting et al., 2011; Neufang et al., 2009; Peper et al., 2009a; Peper et al., 2008). Puberty is characterized by the (re-)activation of the HPG axis. At that time, release of gonadotropin releasing hormone $(\mathrm{GnRH})$ is stimulated and induces, in turn, secretion of luteinizing hormone (LH) and follicle stimulating hormone (FSH) from the pituitary. LH and FSH activate the maturation of the testes and ovaries, and are also associated with the production of the sex steroids testosterone and estrogen, which trigger the maturation of secondary sexual characteristics (Delemarre-van de Waal, 2002; Sisk \& Foster, 2004). We found that 9-year-old girls with the first signs of secondary sexual characteristics already had lower GM density in prefrontal and parietal brain regions compared to 9-year-old girls without the first signs of secondary 
TABLE 3

Main Findings for Cognition and Brain Structure

\begin{tabular}{|c|c|c|c|c|c|}
\hline & & & Methods & & \\
\hline Study & $\begin{array}{l}\text { Age } \\
\text { (years) }\end{array}$ & $\begin{array}{l}\text { Twin/ } \\
\text { sibling }\end{array}$ & $\begin{array}{l}\text { Phenotype } \\
\text { (task/measure } \\
\text { used) }\end{array}$ & $\begin{array}{l}\text { Cross/ } \\
\text { Long }\end{array}$ & Main findings \\
\hline
\end{tabular}

\begin{tabular}{|c|c|c|c|}
\hline $\begin{array}{l}\text { Cognition } \\
\text { van Leeuwen } \\
\quad \text { et al. (2008) }\end{array}$ & $9-14$ & $\begin{array}{l}\text { tw, sib \& } \\
\text { parents }\end{array}$ & - IQ (Raven) \\
\hline $\begin{array}{l}\text { Hoekstra et al. } \\
\qquad(2009)\end{array}$ & $9 \& 18^{a}$ & tw \& sib & $\begin{array}{l}\text { - Verbal learning } \\
\text { (AVLT; CVLT) } \\
\text { - Memory (Corsi, } \\
\text { N-back, DS) } \\
\text { - VIQ (WISC) }\end{array}$ \\
\hline $\begin{array}{l}\text { van Leeuwen } \\
\text { et al. (2009b) }\end{array}$ & $9 \& 18^{a}$ & tw \& sib & $\begin{array}{l}\text { - Working memory } \\
\text { (N-back \& DS } \\
\text { backward) } \\
\text { - STM (Corsi \& DS } \\
\text { forward) }\end{array}$ \\
\hline $\begin{array}{l}\text { van Leeuwen } \\
\text { et al. (2009c) }\end{array}$ & $9-14$ & tw \& sib & $\begin{array}{l}\text { - Reading ability } \\
\text { - IQ (WISC) } \\
\text { - Memory (N-back, } \\
\quad \text { Corsi, DS) }\end{array}$ \\
\hline $\begin{array}{l}\text { van Soelen } \\
\text { et al. (2009) }\end{array}$ & $9-14$ & tw \& sib & $\begin{array}{l}\text { - Verbal learning } \\
\text { (AVLT) }\end{array}$ \\
\hline $\begin{array}{l}\text { van Soelen } \\
\text { et al. (2011c) }\end{array}$ & $9-14$ & tw \& sib & - IQ (WISC) \\
\hline
\end{tabular}

cross The main influence on 10 was genetic; $67 \%$ of 10 variance was accounted for by additive genetic effects; an additional $9 \%$ was due to $\mathrm{G} \times \mathrm{E}$ interaction, with E more important in children with genetic predisposition for low $\mathrm{IQ}$.

cross Heritability for VIQ was high ( $84 \%$ in young children and $82 \%$ in young adults) and for other verbal abilities was moderate (29-55\%); Genetic factors explained the covariance between the different verbal abilities in both cohorts; covariance amongst different verbal tests was stronger in the older cohort than in the younger children.

cross Verbal memory and visuospatial memory were influenced by shared genetic influences; specific A was present as well only in younger children.

cross

cross long

Brain structure

Peper et al. (2009c)

9

tw

- MRI (volumes and VBM)

$\begin{array}{lll}\begin{array}{l}\text { Brouwer et al. } \\ \text { (2010) }\end{array} & 9 & \text { tw } \\ \begin{array}{l}\text { van Soelen } \\ \text { et al. (2010) }\end{array} & 9 & \text { tw } \\ \begin{array}{l}\text { van Soelen } \\ \text { et al. (2011a) }\end{array} & 9-12 & \text { tw }\end{array}$

- DTI (FA,

longitudinal and radial diffusivity) - MTI (MT ratio)

- MRI (volume)

- BW and GA

(questionnaires)

-MRI (volume)

-Height (cm)

cross

cross

long

ng

Brain structure \& hormonal influences

$\begin{array}{lll}\begin{array}{c}\text { Peper et al. } \\ (2008)\end{array} & 9 & \text { tw } \\ \begin{array}{c}\text { Peper et al. } \\ (2009 b)\end{array} & 9 & \text { tw } \\ \begin{array}{c}\text { Peper et al. } \\ (2009 a)\end{array} & 10-14 & \text { sib } \\ \end{array}$

Peper et al. 10-14 sib (2010)

-MRI (volume and cross
VBM)
-LH levels
-MRI (brain volume) cross
-MRI (volume and cross
VBM)
-E, T levels

-MRI (pituitary and cross hypothalamus volume)-LH, FSH, E, T levels
Reading ability was heritable (83\%), and was partly shared with variation in 10 , and memory performance.

Individual differences in verbal learning abilities were moderately heritable; the heritability of LS was $43 \%$ for both twins and siblings; heritability for FS was $20 \%$ in 9-year-old twins and $30 \%$ in the older siblings.

Heritability increased for all IQ scales: FSIQ from $34 \%$ to $65 \%$; VIO from $37 \%$ to $51 \%$; PIQ from $64 \%$ to $72 \%$. Influences of C decreased over time: FSIQ from $43 \%$ to $18 \%$; VIQ from $42 \%$ to $26 \%$; PIQ, C was not significant. Stability of FSIQ $\left(r_{p}=.72\right)$ and VIQ $\left(r_{p}=.72\right)$ was explained by influences of $A$ and $C$. Stability of PIQ $\left(r_{p}=.56\right)$ was completely explained by influences of $A$.

High heritability of global brain volumes (between $77 \%$ for GM, and $94 \%$ for TB). Heritability of lat. vent $35 \%$. Regionally, GM density highly heritable in small areas (Sup, Frontal, Mid. Temporal and amygdala). Heritability of WM more widespread in genu of CC and post. areas of SOF, SLF, Cing. Development of SSC was associated with GM decrease in prefrontal and parietal areas.

FA was not influenced by genetic factors. Significant heritability was found for both radial and longitudinal diffusivity in the genu and splenium of the $\mathrm{CC}$ and the right superior longitudinal fasciculus; heritability estimates if the MTR signal were the largest in the posterior part of the brain.

Shorter GA was associated with a relatively smaller CB volume at age 9; Lower BW was associated with lower $\mathrm{IQ}$ at age 9.

Height and brain volumes were highly heritable at ages $9 / 12$; height (93\%/93\%); e.g., for TB (93\%/96\%). For all brain volumes high $r_{\mathrm{g}}$ over time were observed (> .89); All brain volumes increased, only BB and GM volume decreased $(-1.6 \%)$. Change in volume was heritable for TB $(19 \%), B B(20 \%)$ and $\mathrm{CB}(45 \%)$. Change in $\mathrm{BB}$ volume was associated with change in $\mathrm{CB}\left(r_{\mathrm{p}}=\right.$ $\left..49 ; r_{\mathrm{g}}=.88 ; r_{\mathrm{e}}=.34\right) ;$ Change in height was heritable $(73 \%)$ and partly correlated with changes in $\mathrm{CB}\left(r_{\mathrm{p}}=.24 ; r_{\mathrm{g}}=.48\right)$, but not BB.

$\mathrm{LH}$ associated with global and focal WM increase; in Cing, mid temporal and splenium of CC (in both boys and girls); LH was not associated with GM; association between LH and WM density was driven by common genetic factor.

Having a male co-twin was associated with larger TB, CB and WM (corrected for own sex) compared to female co-twin; Current $T$ and $E$ level could not explain the enlarged brain volumes.

In girls, higher $\mathrm{E}$ levels were related to GM decrease in frontal and parietal areas, and to GM increases in temporal and occipital areas (not to WM). In boys, no association between $T$ or $E$ and brain structure, nor between $T$ and brain structure in girls. Sex differences on GM density were not related to $T$ or E levels.

$\mathrm{LH}, \mathrm{E}$, and T levels increased with age, FSH did not; pituitary volume increased with age. In girls only, pituitary volume was associated with levels of $L H, E$, and $\mathrm{T}$; after correction for age, only FSH was correlated with pituitary volume. Hypothalamic volume did not change with age and was not associated with any hormonal level. 
TABLE 3

Continued

\begin{tabular}{|c|c|c|c|c|c|}
\hline \multirow[b]{2}{*}{ Study } & \multicolumn{4}{|c|}{ Methods } & \multirow[b]{2}{*}{ Main findings } \\
\hline & $\begin{array}{l}\text { Age } \\
\text { (years) }\end{array}$ & $\begin{array}{l}\text { Twin/ } \\
\text { sibling }\end{array}$ & $\begin{array}{l}\text { Phenotype } \\
\text { (task/measure } \\
\text { used) }\end{array}$ & $\begin{array}{l}\text { Cross/ } \\
\text { Long }\end{array}$ & \\
\hline \multicolumn{6}{|c|}{ Brain structure \& cognition } \\
\hline $\begin{array}{l}\text { van Leeuwen } \\
\text { et al. (2009a) }\end{array}$ & 9 & tw & $\begin{array}{l}\text { - MRI (volumes) } \\
\text { - IQ (Raven and } \\
\text { WISC) }\end{array}$ & cross & $\begin{array}{l}\text { Brain volumes and cognitive traits (e.g., IQ) were positively associated with each } \\
\text { other }\left(r_{p}=.20-.33\right) \text {, and were entirely explained by a common set of genes. }\end{array}$ \\
\hline
\end{tabular}

Note: details are given on the included participants (age in years, and whether twins [tw], siblings [sib], or both were included), variables used (phenotype/task/measure used), and the study design (cross-sectional [cross] or longitudinal [long]); $\mathrm{A}=$ additive genetic influences; AVLT = Auditory Verbal Learning Task; $\mathrm{BB}=$ big brain/cerebrum; $\mathrm{BW}=$ birth weight; $\mathrm{C}=$ shared environmental influences; $\mathrm{CB}=\mathrm{cerebellum}$; $\mathrm{CC}=$ corpus callosum; $\mathrm{Cing}$ $=$ cingulum; $C T=$ cortical thickness; $C V L T=$ California Verbal Learning Task; $D S=$ digit span; $E=$ estradiol; $G A=$ gestational age; $F A=$ fractional anisotropy; $\mathrm{FS}=$ forgetting speed; $\mathrm{FSH}=$ follicle stimulating hormone; $\mathrm{GM}=$ gray matter; $\mathrm{IQ}=$ intelligence quotient; Lat $=$ lateral; $\mathrm{LH}=$ luteinizing hormone; LS = learning speed; Mid = middle; Post = posterior; $r_{\mathrm{e}} / \mathrm{r}_{\mathrm{g}} / \mathrm{r}_{\mathrm{p}}=$ unique environmental / genetic / and phenotypic correlations; SOF = superior occipitofrontal fascicle; SLF = superior longitudinal fascicle; $\mathrm{SSC}=$ secondary sexual characteristics; Sup $=$ superior; $\mathrm{T}=$ testosterone; $\mathrm{TB}=$ total brain; VBM = Voxel-based morphometry; WISC = Wechsler Intelligence Scale for children (third version); WM = white matter;

${ }^{a}$ In these studies two cohorts were combined, namely the baseline assessment of the present pediatric cohort and another young adolescent cohort.
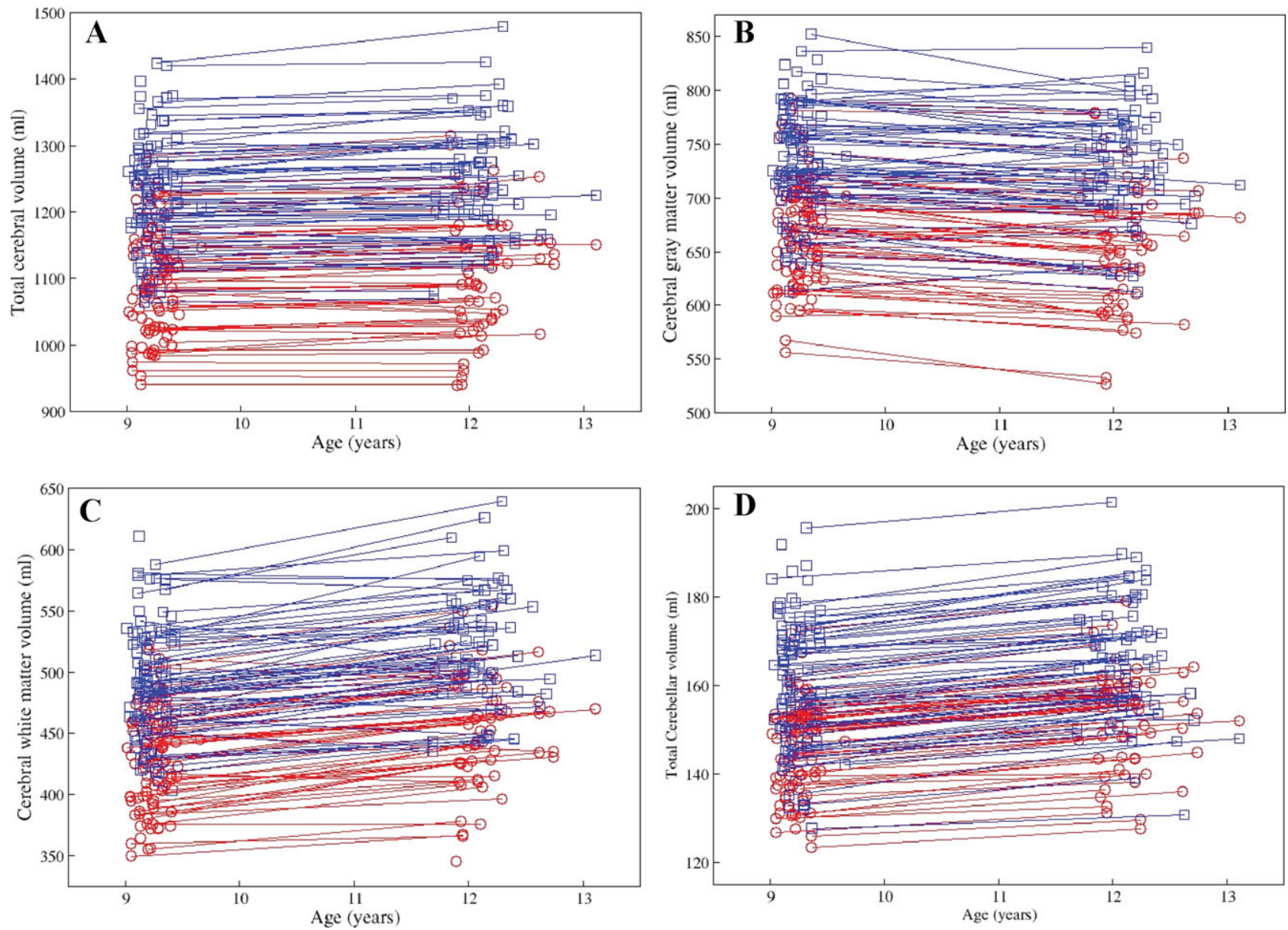

FIGURE 2

Volumetric changes between ages 9 and 12 years. Absolute brain volume of total cerebral volume (A), cerebral gray matter (B), cerebral white matter (C), and total cerebellar volume (D) are given on all included subjects at baseline and at follow-up. Longitudinal data points are connected, with boys depicted in blue, and girls in red (van Soelen et al., 2001a, reprinted with permission). 
sexual characteristics (Peper et al., 2009c). Similar findings were also observed by Bramen et al. (2011), where a more advanced pubertal stage (also assessed by Tanner criteria) was associated with more decrease in cortical GM volume. One of the first endocrinological markers of puberty is $\mathrm{LH}$ secretion during the night. We found that an increased production of $\mathrm{LH}$ at 9 years was associated with larger WM volumes in both sexes (Peper et al., 2008). Regionally, higher levels of LH were associated with greater WM density within the splenium of the corpus callosum, middle temporal gyri, and the cingulum. In addition, this association between WM density and level of LH concentration was explained by overlapping genetic influences acting on both traits (Peper et al., 2008). From this study, it could be concluded that the very first marker of puberty, LH production, predicts WM development.

Effect of estradiol and testosterone were explored in the siblings, aged 10-14 years. In girls, higher estradiol levels were associated with a decrease in GM density in frontal and parietal areas, and with an increase in GM density in temporal and occipital areas (not in WM). There was no effect of testosterone on brain structure in girls. In boys, no association between testosterone or estradiol was found with brain structure (Peper et al., 2009a). In the same group of siblings it was found that pituitary volume was associated with hormonal levels. After correction for age, a larger pituitary volume was associated with higher FSH levels in girls (Peper et al., 2010). Hypothalamic volume did not change with age and was not associated with hormonal levels. To summarize, these studies demonstrate that pubertal hormone levels are associated with GM and WM structure. However, given the large individual differences in puberty onset, longitudinal designs are needed in future research on brain development and sex hormone levels (Blakemore et al., 2010; Peper et al., 2011).

\section{Brain Structure and Cognition}

The relationship of total brain volume and general cognitive abilities has been well established in adults (Deary et al., 2010; Hulshoff Pol et al., 2006; Posthuma et al., 2002). This association is mediated by genes shared between structural brain measures and full scale IQ in adulthood (Hulshoff Pol et al., 2006; Posthuma et al., 2002). In our pediatric twin cohort we demonstrated that this genetic association between brain structure and IQ is already present at a young age. Van Leeuwen et al. (2009a) confirmed the positive association between general cognitive abilities and brain volumes at age $9\left(r_{\mathrm{p}}=.20-.33\right)$, with genetic correlations ranging between .26 and .35 .

\section{Concluding Remarks}

To gain a better understanding of individual differences in brain development, twin studies explore the influence of genetic and environmental factors. This ongoing longitu- dinal project in Dutch twins and siblings aims to develop a more comprehensive view of normative brain development by looking at the effects of genetic and environmental influences on different aspects of brain structure and cognition around puberty. Below we discuss how these results may be viewed in the light of current knowledge of healthy development, and developmental models of psychopathology.

Because the majority of psychiatric disorders emerge during adolescence (Shaw et al., 2010; Gogtay et al., 2002), understanding the relative influences of genetic and environmental effects on brain development during this crucial period may elucidate biological processes underlying these illnesses. Why an individual develops a psychiatric disorder is a result of genetic predisposition and environmental factors that a person may encounter early or later in life. Crosssectional studies are limited with respect to information regarding the developmental trajectory of individual brains (Karmiloff-Smith, 2010). Because of this, longitudinal studies are of great importance. Mapping normal development can create opportunities for modeling disrupted trajectories in psychopathology (Gogtay \& Thompson, 2010; Shaw et al., 2007; Shaw et al., 2010; Wallace et al., 2010). Future research should focus on the developmental changes of the human brain, and the genetic and environmental influences that can act upon these changes. When selecting phenotypes to map brain development, it is important to analyze brain measures that capture different aspects of brain structure like cortical volume, surface area, cortical thickness, sulcal depth, and measures of cortical folding or gyrification, which all have a genetic component (Kochunov et al., 2010; Rogers et al., 2007; Rogers et al., 2010). Age-related changes in heritability observed for measures of brain structures or cognitive functioning (Lenroot et al., 2009; van Soelen et al., 2011c; Wallace et al., 2006) can be linked to the timing of gene expression patterns, and this, in turn, might be related to the age of onset of disorders. Identifying the actual genes that are involved in developmental changes of brain structure and function is the next challenge.

Our study focuses on multiple aspects of structural brain changes and cognition, and is one of the few to explore how changes in brain anatomy are linked to cognitive functions from a genetic perspective at specific ages. Shaw et al. (2006) showed that cortical thickness trajectories between childhood and adolescence (ages 4 to 17 years) differed based on the level of intelligence, giving one of the first indications that the developmental trajectory of cortical thickness is associated with cognitive ability. Performance on different cognitive tasks indicative for executive control was associated with the amount of thinning observed in a large cross-sectional sample of children from 8 to 19 years old (Tamnes et al., 2010). A recent study indicated that changes in IQ during adolescence was associated with changes in GM volume, indicating the importance of large individual differences in brain developmental trajectories, and how this is linked with changes in cognitive 
performance (Ramsden et al., 2011). Heritability for local cortical thickness throughout the cortex was previously reported in children (Lenroot et al., 2009; Yoon et al., 2010) and adults (Brans et al., 2010; Kremen et al., 2010; Panizzon et al., 2009; Rimol et al., 2010). The study of Lenroot et al., consisting of a sample with a large age range from 5 to 19 years, observed indirect indications that the increase of heritability seems to be related to the timing of maturation processes. We are currently exploring the genetics of changes in cortical thickness (van Soelen et al., 2011b), and its genetic relation with intelligence in our cohort.

How the maturation processes of structural and functional brain changes in adolescents are linked together, and how these reflect or interact with improvement in cognitive abilities, remain to be elucidated. Cognitive maturation during adolescence may not be a direct reflection of brain regions that mature at different ages, but rather a reflection of the development of networks enabling more efficient strategies to perform a task (e.g., Casey et al., 2005a; Durston et al., 2006). Many studies nowadays also explore the connectivity of the brain at rest (van den Heuvel \& Hulshoff Pol, 2010; van den Heuvel et al., 2009). A rapidly increasing number of studies now illustrate that indeed the development of the brain is not only reflected by structural changes, but is also associated with changes in connectivity between brain regions (Dosenbach et al., 2010; Fair et al., 2009; Supekar et al., 2009; Supekar et al., 2010; Power et al., 2010). Furthermore, genetic influences on brain activity at rest have been found (Fornito et al., 2011; Glahn et al., 2010; Smit et al., 2008), and during performance of cognitive tasks (Blokland et al., 2011; Koten et al., 2009).

It is important to embrace longitudinal projects and to continue ongoing projects that assess brain development and related phenotypes. Following a large group of children for several years is time-consuming and expensive, and researchers face challenges to avoid drop-outs. Our cohort is one of a few pediatric family cohorts that allow the modeling of genetic influences across multiple ages in childhood and puberty. The participants will be invited for a second follow-up. This will bring new opportunities for nonlinear modeling of brain changes and cognitive functioning, and for exploring brain function with functional MRI. This will provide a better understanding of how individual differences in brain development occur during the transition from childhood into adolescence.

\section{Acknowledgments and Funding}

We would like to thank all the participants for making this study possible. This work was supported by The Netherlands Organization for Scientific Research (NWO 51.02.060 (H.H.), 668.772 (D.B.); NWO-MagW 480-04-004 (D.B.); NWO/SPI 56-464-14192 (D.B.); NWO/Veni 451-10-007 (J.S.P.)), the European Research Council (ERC-230374) (D.B.), High Potential Grant Utrecht University (H.H.) and with the support of the Neuroscience Campus Amsterdam (NCA).

\section{References}

Achenbach, T. M. (1991). Manual for the Child Behavior Checklist/ 4-18 and 1991 Profile. Burlington, VT: Department of Psychiatry, University of Vermont.

Achenbach, T. M., \& Rescorla, L. A. (2001). Manual for the ASEBA School-age Forms \& Profiles. Burlington VT: Research Center for Children, Youth \& Families, University of Vermont.

Akil, H., Martone, M. E., \& Van, E. (2011). Challenges and opportunities in mining neuroscience data. Science, 331, 708-712.

Baron-Cohen, S., Wheelwright, S., Hill, J., Raste, Y., \& Plumb, I. (2001). The 'Reading the Mind in the Eyes' test revised version: A study with normal adults, and adults with Asperger syndrome or high-functioning autism. Journal of Child Psychology and Psychiatry and Allied Disciplines, 42, 241-251.

Bartels, M., de Geus, E. J., Kirschbaum, C., Sluyter, F., \& Boomsma, D. I. (2003). Heritability of daytime cortisol levels in children. Behavior Genetics, 33, 421-433.

Bartels, M., van Beijsterveldt, C. E., \& Boomsma, D. I. (2009). Breastfeeding, maternal education and cognitive function: A prospective study in twins. Behavior Genetics, 39, 616622.

Bartels, M., van Beijsterveldt, C. E., Derks, E. M., Stroet, T. M., Polderman, T. J., Hudziak, J. J., \& Boomsma, D. I. (2007). Young Netherlands Twin Register (Y-NTR): A longitudinal multiple informant study of problem behavior. Twin Research and Human Genetics, 10, 3-11.

Bartzokis, G., Beckson, M., Lu, P. H., Nuechterlein, K. H., Edwards, N., \& Mintz, J. (2001). Age-related changes in frontal and temporal lobe volumes in men: A magnetic resonance imaging study. Archives of General Psychiatry, 58, 461-465.

Benes, F. M., Turtle, M., Khan, Y., \& Farol, P. (1994). Myelination of a key relay zone in the hippocampal formation occurs in the human brain during childhood, adolescence, and adulthood. Archives of General Psychiatry, 51, 477-484.

Bienvenu, O. J., Davydow, D. S., \& Kendler, K. S. (2011). Psychiatric 'diseases' versus behavioral disorders and degree of genetic influence. Psychological Medicine, 41, 33-40.

Blakemore, S. J., Burnett, S., \& Dahl, R. E. (2010). The role of puberty in the developing adolescent brain. Human Brain Mapping, 31, 926-933.

Blokland, G. A., McMahon, K. L., Thompson, P. M., Martin, N. G., de Zubicaray, G. I., \& Wright, M. J. (2011). Heritability of working memory brain activation. Journal of Neuroscience, 31, 10882-10890.

Boomsma, D. I., de Geus, E. J., Vink, J. M., Stubbe, J. H., Distel, M. A., Hottenga, J. J., Posthuma, D., van Beijsterveldt, T. C., Hudziak, J. J., Bartels, M., \& Willemsen, G. (2006). Netherlands Twin Register: From twins to twin families. Twin Research and Human Genetics, 9, 849-857. 
Boomsma, D. I., van Beijsterveldt, C. E., \& Hudziak, J. J. (2005). Genetic and environmental influences on Anxious/Depression during childhood: A study from The Netherlands Twin Register. Genes, Brain and Behavior, 4, 466-481.

Bramen, J. E., Hranilovich, J. A., Dahl, R. E., Forbes, E. E., Chen, J., Toga, A. W., Dinov, I. D., Worthman, C. M., \& Sowell, E. R. (2011). Puberty influences medial temporal lobe and cortical gray matter maturation differently in boys than girls matched for sexual maturity. Cerebral Cortex, 21, 636-646.

Brans, R. G., Kahn, R. S., Schnack, H. G., van Baal, G. C., Posthuma, D., van Haren, N. E., Lepage, C., Lerch, J. P., Collins, D. L., Evans, A. C., Boomsma, D. I., \& Hulshoff Pol, H. E. (2010). Brain plasticity and intellectual ability are influenced by shared genes. Journal of Neuroscience, 30, 5519-5524.

Brouwer, R. M., Mandl, R. C., Peper, J. S., van Baal, G. C., Kahn, R. S., Boomsma, D. I., \& Hulshoff Pol, H. E. (2010). Heritability of DTI and MTR in nine-year-old children. Neuroimage, 53, 1085-1092.

Brouwer, S. I., van Beijsterveldt, T. C., Bartels, M., Hudziak, J. J., \& Boomsma, D. I. (2006). Influences on achieving motor milestones: A twin-singleton study. Twin Research and Human Genetics, 9, 424-430.

Casey, B. J., Galvan, A., \& Hare, T. A. (2005a). Changes in cerebral functional organization during cognitive development. Current Opinion in Neurobiology, 15, 239-244.

Casey, B. J., Tottenham, N., Liston, C., \& Durston, S. (2005b). Imaging the developing brain: What have we learned about cognitive development? Trends in Cognitive Sciences, 9, 104110.

Cito (1995). Drie minuten leestest. Arnhem: Cito.

Corsi, P. M. (1974). Human memory and the medial temporal region of the brain. Dissertation Abstracts International, 34, 819B (University Microfilms No. AAI05-77717).

Crone, E. A. (2009). Executive functions in adolescence: Inferences from brain and behavior. Developmental Science, 12, 825-830.

Deary, I. J., Penke, L., \& Johnson, W. (2010). The neuroscience of human intelligence differences. Nature Reviews Neuroscience, 11, 201-211.

Delemarre-van de Waal, H. (2002). Regulation of puberty. Best Practice and Research Clinical Endocrinology and Metabolism, 16, 1-12.

Demetriou, A., Christou, C., Spanoudis, G., \& Platsidou, M. (2002). The development of mental processing: Efficiency, working memory, and thinking. Monographs of the Society for Research in Child Development, 67, Serial Number 268.

de Zeeuw, L. E. J., van Beijsterveldt, C. E. M., de Geus, E. J. C., \& Boomsma, D. I. (2012). Twin specific risk factors in primary school achievements. Manuscript submitted for publication.

Dosenbach, N. U., Nardos, B., Cohen, A. L., Fair, D. A., Power, J. D., Church, J. A., Nelson, S. M., Wig, G. S., Vogel, A. C., Lessov-Schlaggar, C. N., Barnes, K. A., Dubis, J. W., Feczko, E., Coalson, R. S., Pruett, J. R., Jr., Barch, D. M., Petersen, S. E., \& Schlaggar, B. L. (2010). Prediction of individual brain maturity using fMRI. Science, 329, 1358-1361.
Durston, S., Davidson, M. C., Tottenham, N., Galvan, A., Spicer, J., Fossella, J. A., \& Casey, B. J. (2006). A shift from diffuse to focal cortical activity with development. Developmental Science, 9, 1-8.

Durston, S., Nederveen, H., van Dijk, S., van Belle, J., de Zeeuw, P., Langen, M., \& van Dijk, A. (2009). Magnetic resonance simulation is effective in reducing anxiety related to magnetic resonance scanning in children. Journal of the American Academy of Child and Adolescent Psychiatry, 48, 206-207.

Eriksen, B. A., \& Eriksen, C. W. (1974). Effects of noise letters upon identification of a target letter in a nonsearch task. Perception \& Psychophysics, 16, 143-149.

Eriksen, C. W., \& Schultz, D. W. (1979). Information processing in visual-search-continuous-flow conception and experimental results. Perception \& Psychophysics, 25, 249263.

Estourgie-van Burk, G. F., Bartels, M., Boomsma, D. I., \& Delemarre-van de Waal, H. A. (2010). Body size of twins compared with siblings and the general population: From birth to late adolescence. Journal of Pediatrics, 156, 586-591.

Fair, D. A., Cohen, A. L., Power, J. D., Dosenbach, N. U., Church, J. A., Miezin, F. M., Schlaggar, B. L., \& Petersen, S. E. (2009). Functional brain networks develop from a 'local to distributed' organization. PLoS Computational Biology, 5, e1000381.

Faraone, S. V., Perlis, R. H., Doyle, A. E., Smoller, J. W., Goralnick, J. J., Holmgren, M. A., \& Sklar, P. (2005). Molecular genetics of attention-deficit/hyperactivity disorder. Biological Psychiatry, 57, 1313-1323.

Felsenfeld, S., van Beijsterveldt, C. E., \& Boomsma, D. I. (2010). Attentional regulation in young twins with probable stuttering, high nonfluency, and typical fluency. Journal of Speech, Language, and Hearing Research, 53, 1147-1166.

Fornito, A., Zalesky, A., Bassett, D. S., Meunier, D., EllisonWright, I., Yucel, M., Wood, S. J., Shaw, K., O’ Connor, J., Nertney, D., Mowry, B. J., Pantelis, C., \& Bullmore, E. T. (2011). Genetic influences on cost-efficient organization of human cortical functional networks. Journal of Neuroscience, 31, 3261-3270.

Franic, S., Middeldorp, C. M., Dolan, C. V., Ligthart, L., \& Boomsma, D. I. (2010). Childhood and adolescent anxiety and depression: Beyond heritability. Journal of the American Academy of Child and Adolescent Psychiatry, 49, 820-829.

Gathercole, S. E., Pickering, S. J., Ambridge, B., \& Wearing, H. (2004). The structure of working memory from 4 to 15 years of age. Developmental Psychology, 40, 177-190.

Gevins, A., \& Cutillo, B. (1993). Spatiotemporal dynamics of component processes in human working memory. Electroencephalography and Clinical Neurophysiology, 87, 128-143.

Giedd, J. N., Blumenthal, J., Jeffries, N. O., Castellanos, F. X., Liu, H., Zijdenbos, A., Paus, T., Evans, A. C., \& Rapoport, J. L. (1999). Brain development during childhood and adolescence: A longitudinal MRI study. Nature Neuroscience, 2, 861-863.

Giedd, J. N., Clasen, L. S., Lenroot, R., Greenstein, D., Wallace, G. L., Ordaz, S., Molloy, E. A., Blumenthal, J. D., 
Tossell, J. W., Stayer, C., Samango-Sprouse, C. A., Shen, D., Davatzikos, C., Merke, D., Chrousos, G. P. (2006). Puberty-related influences on brain development. Molecular and Cellular Endocrinology, 254-255, 154-162.

Glahn, D. C., Winkler, A. M., Kochunov, P., Almasy, L., Duggirala, R., Carless, M. A., Curran, J. C., Olvera, R. L., Laird, A. R., Smith, S. M., Beckmann, C. F., Fox, P. T., \& Blangero, J. (2010). Genetic control over the resting brain. Proceedings of the National Academy of Sciences USA, 107, 1223-1228.

Gogtay, N., Giedd, J. N., Lusk, L., Hayashi, K. M., Greenstein, D., Vaituzis, A. C., Nugent, T. F., Herman, D. H., Clasen, L. S., Toga, A. W., Rapoport, J. L., \& Thompson, P. M. (2004). Dynamic mapping of human cortical development during childhood through early adulthood. Proceedings of the National Academy of Sciences USA, 101, 81748179.

Gogtay, N., Giedd, J., \& Rapoport, J. L. (2002). Brain development in healthy, hyperactive, and psychotic children. Archives of Neurology, 59, 1244-1248.

Gogtay, N., \& Thompson, P. M. (2010). Mapping gray matter development: Implications for typical development and vulnerability to psychopathology. Brain and Cognition, 72, 6-15.

Gur, R. C., Ragland, J. D., Moberg, P. J., Turner, T. H., Bilker, W. B., Kohler, C., Siegel, S. J., \& Gur, R. E. (2001). Computerized neurocognitive scanning: I. Methodology and validation in healthy people. Neuropsychopharmacology, 25, 766-776.

Gur, R. C., Richard, J., Hughett, P., Calkins, M. E., Macy, L., Bilker, W. B., Brensinger, C., \& Gur, R. E. (2010). A cognitive neuroscience-based computerized battery for efficient measurement of individual differences: Standardization and initial construct validation. Journal of Neuroscience Methods, 187, 254-262.

Herting, M. M., Maxwell, E. C., Irvine, C., \& Nagel, B. J. (2011). The impact of sex, puberty, and hormones on white matter microstructure in adolescents. Cerebral Cortex, Oct 14. [Epub ahead of print] Retrieved from http://www.ncbi.nlm.nih.gov/pubmed/22002939

Hoekstra, R. A., Bartels, M., Cath, D. C., \& Boomsma, D. I. (2008). Factor structure, reliability and criterion validity of the Autism-Spectrum Quotient (AQ): A study in Dutch population and patient groups. Journal of Autism and Developmental Disorders, 38, 1555-1566.

Hoekstra, R. A., Bartels, M., van Leeuwen, M., \& Boomsma, D. I. (2009). Genetic architecture of verbal abilities in children and adolescents. Developmental Science, 12, 1041-1053.

Hulshoff Pol, H. E., Schnack, H. G., Posthuma, D., Mandl, R. C., Baare, W. F., van Oel, C., van Haren, N. E., Collins, D. L., Evans, A. C., Amunts, K., Burgel, U., Zilles, K., De Geus, E., Boomsma, D. I., \& Kahn, R. S. (2006). Genetic contributions to human brain morphology and intelligence. Journal of Neuroscience, 26, 10235-10242.

Huttenlocher, P. R., \& Dabholkar, A. S. (1997). Regional differences in synaptogenesis in human cerebral cortex. Journal of Comparative Neurology, 387, 167-178.

Insel, T. R. (2010). Rethinking schizophrenia. Nature, 468, 187-193.
Jansma, J. M., Ramsey, N. F., Coppola, R., \& Kahn, R. S. (2000). Specific versus nonspecific brain activity in a parametric $\mathrm{N}$ back task. Neuroimage, 12, 688-697.

Karmiloff-Smith, A. (2010). Neuroimaging of the developing brain: Taking 'developing' seriously. Human Brain Mapping, 31, 934-941.

Keating, D. (2004). Cognitive and brain development. In L. Steinberg (Ed.), Handbook of adolescent psychology (2nd ed.). New York: Wiley.

Kessler, R. C., Angermeyer, M., Anthony, J. C., de Graff, R., Demyttenaere, K., Gasquet, I., de Girolamo, G., Gluzman, S., Gureje, O., Haro, J. M., Kawakami, N., Karam, A., Levinson, D., Medina Mora, M. E., Oakley Browne, M. A., PosadaVilla, J., Stein, D. J., Adley Tsang, C. H., Aguilar-Gaxiola, S., Alonso, J., Lee, S., Heeringa, S., Pennell, B. E., Berglund, P., Gruber, M. J., Petukhova, M., Chatterji, S., \& Ustün, T. B. (2007). Lifetime prevalence and age-of-onset distributions of mental disorders in the World Health Organization's World Mental Health Survey Initiative. World Psychiatry, 6, 168-176.

Kochunov, P., Glahn, D. C., Fox, P. T., Lancaster, J. L., Saleem, K., Shelledy, W., Zilles, K., Thompson, P. M., Coulon, O., Mangin, J. F., Blangero, J., \& Rogers, J. (2010). Genetics of primary cerebral gyrification: Heritability of length, depth and area of primary sulci in an extended pedigree of Papio baboons. Neuroimage, 53, 1126-1134.

Koten, J. W., Wood, G., Hagoort, P., Goebel, R., Propping, P., Willmes, K., \& Boomsma, D. I. (2009). Genetic contribution to variation in cognitive function: an FMRI study in twins. Science, 323, 1737-1740.

Kremen, W. S., Prom-Wormley, E., Panizzon, M. S., Eyler, L. T., Fischl, B., Neale, M. C., Franz, C. E., Lyons, M. J., Pacheco, J., Perry, M. E., Stevens, A., Schmitt, J. E., Grant, M. D., Seidman, L. J., Thermenos, H. W., Tsuang, M. T., Eisen, S. A., Dale, A. M., \& Fennema-Notestine, C. (2010). Genetic and environmental influences on the size of specific brain regions in midlife: The VETSA MRI study. Neuroimage, 49, 1213-1223.

Lebel, C., \& Beaulieu, C. (2011). Longitudinal development of human brain wiring continues from childhood into adulthood. Journal of Neuroscience, 31, 10937-10947.

Lenroot, R. K., Gogtay, N., Greenstein, D. K., Wells, E. M., Wallace, G. L., Clasen, L. S., Blumenthal, J. D., Lerch, J., Zijdenbos, A. P., Evans, A. C., Thompson, P. M., \& Giedd, J. N. (2007). Sexual dimorphism of brain developmental trajectories during childhood and adolescence. Neuroimage, 36, 1065-1073.

Lenroot, R. K., Schmitt, J. E., Ordaz, S. J., Wallace, G. L., Neale, M. C., Lerch, J. P., Kendler, K. S., Evans, A. C., \& Giedd, J. N. (2009). Differences in genetic and environmental influences on the human cerebral cortex associated with development during childhood and adolescence. Human Brain Mapping, 30, 163-174.

Limperopoulos, C., Soul, J. S., Gauvreau, K., Huppi, P. S., Warfield, S. K., Bassan, H., Robertson, R. L., Volpe, J. J., \& du Plessis, A. J. (2005). Late gestation cerebellar growth is rapid and impeded by premature birth. Pediatrics, 115, 688-695. 
Luciano, M., Smith, G. A., Wright, M. J., Geffen, G. M., Geffen, L. B., \& Martin, N. G. (2001). On the heritability of inspection time and its covariance with IQ: A twin study. Intelligence, 29, 443-457.

Luna, B., \& Sweeney, J. A. (2001). Studies of brain and cognitive maturation through childhood and adolescence: A strategy for testing neurodevelopmental hypotheses. Schizophrenia Bulletin, 27, 443-455.

Marshall, W. A., \& Tanner, J. M. (1969). Variations in pattern of pubertal changes in girls. Archives of Diseases in Childhood, 44, 291-303.

Marshall, W. A., \& Tanner, J. M. (1970). Variations in the pattern of pubertal changes in boys. Archives of Diseases in Childhood, 45, 13-23.

Muhle, R., Trentacoste, S. V., \& Rapin, I. (2004). The genetics of autism. Pediatrics, 113, e472-e486.

Neufang, S., Specht, K., Hausmann, M., Gunturkun, O., Herpertz-Dahlmann, B., Fink, G. R., \& Konrad, K. (2009). Sex differences and the impact of steroid hormones on the developing human brain. Cerebral Cortex, 19, 464-473.

Oldfield, R. C. (1971). The assessment and analysis of handedness: The Edinburgh inventory. Neuropsychologia, 9, 97113.

Panizzon, M. S., Fennema-Notestine, C., Eyler, L. T., Jernigan, T. L., Prom-Wormley, E., Neale, M., Jacobson, K., Lyons, M. J., Grant, M. D., Franz, C. E., Xian, H., Tsuang, M., Fischl, B., Seidman, L., Dale, A., \& Kremen, W. S. (2009). Distinct genetic influences on cortical surface area and cortical thickness. Cerebral Cortex, 19, 2728-2735.

Paus, T. (2005). Mapping brain maturation and cognitive development during adolescence. Trends in Cognitive Science, 9, 60-68.

Paus, T., Keshavan, M., \& Giedd, J. N. (2008). Why do many psychiatric disorders emerge during adolescence? Nature Reviews Neuroscience, 9, 947-957.

Peper, J. S., Brouwer, R. M., Schnack, H. G., van Baal, G. C., van Leeuwen, M., van den Berg, S. M., Delemarre-van de Waal, H. A., Boomsma, D. I., Kahn, R. S., \& Hulshoff Pol, H. E. (2009a). Sex steroids and brain structure in pubertal boys and girls. Psychoneuroendocrinology, 34, 332-342.

Peper, J. S., Brouwer, R. M., Schnack, H. G., van Baal, G. C., van Leeuwen, M., van den Berg, S. M., Delemarre-van de Waal, H. A., Janke, A. L., Collins, D. L., Evans, A. C., Boomsma, D. I., Kahn, R. S., \& Hulshoff Pol, H. E. (2008). Cerebral white matter in early puberty is associated with luteinizing hormone concentrations. Psychoneuroendocrinology, 33, 909-915.

Peper, J. S., Brouwer, R. M., van Baal, G. C., Schnack, H. G., van Leeuwen, M., Boomsma, D. I., Kahn, R. S., \& Hulshoff Pol, H. E. (2009b). Does having a twin brother make for a bigger brain? European Journal of Endocrinology, 160, 739-746.

Peper, J. S., Brouwer, R. M., van Leeuwen, M., Schnack, H. G., Boomsma, D. I., Kahn, R. S., \& Hulshoff Pol, H. E. (2010). HPG axis hormones during puberty: A study on the association with hypothalamic and pituitary volumes. Psychoneuroendocrinology, 35, 133-140.

Peper, J. S., Hulshoff Pol, H. E., Crone, E. A., \& Honk, J. (2011) Sex steroids and brain structure in pubertal boys and girls:
A mini-review of neuroimaging studies. Neuroscience, 191, 28-37.

Peper, J. S., Schnack, H. G., Brouwer, R. M., van Baal, G. C., Pjetri, E., Szekely, E., van Leeuwen, M., van den Berg, S. M., Collins, D. L., Evans, A. C., Boomsma, D. I., Kahn, R. S., \& Hulshoff Pol, H. E. (2009c). Heritability of regional and global brain structure at the onset of puberty: A magnetic resonance imaging study in 9-year-old twin pairs. Human Brain Mapping, 30, 2184-2196.

Posthuma, D., de Geus, E. J., Baare, W. F., Hulshoff Pol, H. E., Kahn, R. S., \& Boomsma, D. I. (2002). The association between brain volume and intelligence is of genetic origin. Nature Neuroscience, 5, 83-84.

Power, J. D., Fair, D. A., Schlaggar, B. L., \& Petersen, S. E. (2010). The development of human functional brain networks. Neuron, 67, 735-748.

Ramsden, S., Richardson, F. M., Josse, G., Thomas, M. S. C., Ellis, C., Shakeshaft, C., Seghier, M. L., \& Price, C. J. (2011). Verbal and non-verbal intelligence changes in the teenage brain. Nature, 479, 113-116.

Raven, J. C. (1960). Guide to the Standard Progressive Matrices. London: H.K. Lewis.

Raven, J., Raven, J. C., \& Court, J. H. (1998). Raven manual: Section 4 Advanced Progressive Matrices. (1998 ed.) Oxford: Oxford Psychologists Press.

Read, G. F., Walker, R. F., Wilson, D. W., \& Griffiths, K. (1990). Steroid analysis in saliva for the assessment of endocrine function. Annals of the New York Academy of Sciences, 595, 260-274.

Riad-Fahmy, D., Read, G. F., Walker, R. F., Walker, S. M., \& Griffiths, K. (1987). Determination of ovarian steroid hormone levels in saliva. An overview. Journal of Reproductive Medicine, 32, 254-272.

Rimol, L. M., Panizzon, M. S., Fennema-Notestine, C., Eyler, L. T., Fischl, B., Franz, C. E., Hagler, D. J., Lyons, M. J., Neale, M. C., Pacheco, J., Perry, M. E., Schmitt, J. E., Grant, M. D., Seidman, L. J., Thermenos, H. W., Tsuang, M. T., Eisen, S. A., Kremen, W. S., \& Dale, A. M. (2010). Cortical thickness is influenced by regionally specific genetic factors. Biological Psychiatry, 67, 493-499.

Rogers, J., Kochunov, P., Lancaster, J., Shelledy, W., Glahn, D., Blangero, J., \& Fox, P. (2007). Heritability of brain volume, surface area and shape: An MRI study in an extended pedigree of baboons. Human Brain Mapping, 28, 576-583.

Rogers, J., Kochunov, P., Zilles, K., Shelledy, W., Lancaster, J., Thompson, P., Duggirala, R., Blangero, J., Fox, P. T., \& Glahn, D. C. (2010). On the genetic architecture of cortical folding and brain volume in primates. Neuroimage, 53, 1103-1108.

Schmitt, J. E., Eyler, L. T., Giedd, J. N., Kremen, W. S., Kendler, K. S., \& Neale, M. C. (2007). Review of twin and family studies on neuroanatomic phenotypes and typical neurodevelopment. Twin Research and Human Genetics, 10, 683-694.

Shaw, P., Eckstrand, K., Sharp, W., Blumenthal, J., Lerch, J. P., Greenstein, D., Clasen, L., Evans, A., Giedd, J., \& Rapoport, J. L. (2007). Attention-deficit/hyperactivity disorder is characterized by a delay in cortical maturation. Proceedings of the National Academy of Sciences USA, 104, 19649-19654. 
Shaw, P., Gogtay, N., \& Rapoport, J. (2010). Childhood psychiatric disorders as anomalies in neurodevelopmental trajectories. Human Brain Mapping, 31, 917-925.

Shaw, P., Greenstein, D., Lerch, J., Clasen, L., Lenroot, R., Gogtay, N., Evans, A., Rapoport, J., \& Giedd, J. (2006). Intellectual ability and cortical development in children and adolescents. Nature, 440, 676-679.

Simon, H. A. (1975). Functional equivalence of problem solving skills. Cognitive Psychology, 7, 268-288.

Sisk, C. L., \& Foster, D. L. (2004). The neural basis of puberty and adolescence. Nature Neuroscience, 7, 1040-1047.

Smit, D. J., Stam, C. J., Posthuma, D., Boomsma, D. I., \& de Geus, E. J. (2008). Heritability of 'small-world' networks in the brain: A graph theoretical analysis of resting-state EEG functional connectivity. Human Brain Mapping, 29, 1368-1378.

Sowell, E. R., Trauner, D. A., Gamst, A., \& Jernigan, T. L. (2002). Development of cortical and subcortical brain structures in childhood and adolescence: A structural MRI study. Developmental Medicine and Child Neurology, 44, 4-16.

Steinberg, L. (2005). Cognitive and affective development in adolescence. Trends in Cognitive Science, 9, 69-74.

Stroop, J. R. (1935). Studies of interference in serial verbal reactions. Journal of Experimental Psychology, 18, 643-662.

Supekar, K., Musen, M., \& Menon, V. (2009). Development of large-scale functional brain networks in children. PLoS Biology, 7, e1000157.

Supekar, K., Uddin, L. Q., Prater, K., Amin, H., Greicius, M. D., \& Menon, V. (2010). Development of functional and structural connectivity within the default mode network in young children. Neuroimage, 52, 290-301.

Tamnes, C. K., Ostby, Y., Fjell, A. M., Westlye, L. T., Due-Tonnessen, P., \& Walhovd, K. B. (2010). Brain maturation in adolescence and young adulthood: Regional agerelated changes in cortical thickness and white matter volume and microstructure. Cerebral Cortex, 20, 534-548.

Tanner, J. M., \& Whitehouse, R. H. (1976). Clinical longitudinal standards for height, weight, height velocity, weight velocity, and stages of puberty. Archives of Diseases in Childhood, 51, 170-179.

Tiemeier, H., Lenroot, R. K., Greenstein, D. K., Tran, L., Pierson, R., \& Giedd, J. N. (2010). Cerebellum development during childhood and adolescence: A longitudinal morphometric MRI study. Neuroimage, 49, 63-70.

van Beijsterveldt, C. E., \& Boomsma, D. I. (2007). Genetics of parentally reported asthma, eczema and rhinitis in 5-yr-old twins. European Respiratory Journal, 29, 516-521.

van den Burg, W., \& Kingma, A. (1999). Performance of 225 Dutch school children on Rey's Auditory Verbal Learning Test (AVLT): Parallel test-retest reliabilities with an interval of 3 months and normative data. Archives of Clinical Neuropsychology, 14, 545-559.

van den Heuvel, M. P. \& Hulshoff Pol, H. E. (2010). Exploring the brain network: A review on resting-state fMRI functional connectivity. European Neuropsychopharmacology, 20, 519-534.

van den Heuvel, M. P., Mandl, R. C., Kahn, R. S., \& Hulshoff Pol, H. E. (2009). Functionally linked resting-state networks reflect the underlying structural connectivity architecture of the human brain. Human Brain Mapping, 30, 3127-3141.

van Leeuwen, M., Peper, J. S., van den Berg, S. M., Brouwer, R. M., Hulschoff Pol, E. H., Kahn, R. S., \& Boomsma, D. I. (2009a). A genetic analysis of brain volumes and IQ in children. Intelligence, 37, 181-191.

van Leeuwen, M., van den Berg, S. M., \& Boomsma, D. I. (2008). A twin-family study of general IQ. Learning and Individual Differences, 18, 76-88.

van Leeuwen, M., van den Berg, S. M., Hoekstra, R. A., \& Boomsma, D. I. (2007). Endophenotypes for intelligence in children and adolescents. Intelligence, 35, 369-380.

van Leeuwen, M., van den Berg, S. M., Hoekstra, R. A., \& Boomsma, D. I. (2009b). The genetic and environmental structure of verbal and visuospatial memory in young adults and children. Neuropsychology, 23, 792-802.

van Leeuwen, M., van den Berg, S. M., Peper, J. S., Hulschoff Pol, H. E., \& Boomsma, D. I. (2009c). Genetic covariance structure of reading, intelligence and memory in children. Behavior Genetics, 39, 245-254.

van Leijenhorst, L., Moor, B. G., de Macks, Z. A. O., Rombouts, S. A. R. B., Westenberg, P. M., \& Crone, E. A. (2010). Adolescent risky decision-making: Neurocognitive development of reward and control regions. Neuroimage, $51,345-355$.

van Soelen, I. L. C., Brouwer, R. M., Peper, J. S., van Beijsterveldt, T. C., van, L. M., de Vries, L. S., Kahn, R. S., Hulshoff Pol, H. E., \& Boomsma, D. I. (2010). Effects of Gestational Age and Birth Weight on Brain Volumes in Healthy 9 Year-Old Children. Journal of Pediatrics, 156, 896-901.

van Soelen, I. L. C., Brouwer, R. M., van Baal, G. C. M., Schnack, H. G., Peper, J. S., Chen, L., Kahn, R. S., Boomsma, D. I., \& Hulshoff Pol, H. E. (2011a). Heritability of volumetric brain changes and height in children entering puberty. Human Brain Mapping. doi:10.1002/hbm.21468

van Soelen, I. L. C., Brouwer, R. M., van Baal, G. C. M., Schnack, H. G., Peper, J. S., Collins, D. L., Evans, A., Kahn, R. S., Boomsma, D. I., \& Hulshoff Pol, H. E. (2011b). Genetic influences on thinning of the cerebral cortex during development. NeuroImage, 59, 3871-3880.

van Soelen, I. L. C., Brouwer, R. M., van Leeuwen, M., Kahn, R. S., Hulshoff Pol, H. E., \& Boomsma, D. I. (2011c). Heritability of verbal and performance intelligence in a pediatric longitudinal sample. Twin Research and Human Genetics, $14,119-128$.

van Soelen, I. L. C., van den Berg, S. M., Dekker, P. H., van Leeuwen, M., Peper, J. S., Hulschoff Pol, H. E., \& Boomsma, D. I. (2009). Individual differences in dynamic measures of verbal learning abilities in young twin pairs and their older siblings. Learning and Individual Differences, 19, 440-444.

Verhulst, F. C., van der Ende, J., \& Koot, H. M. (1997). Handleiding voor de Youth Self Report (YSR) [Dutch manual for the YSR]. Rotterdam, The Netherlands: Academic Medical Center, Rotterdam / Erasmus University, Sophia Children's Hospital, Department of Child Psychiatry. 
Walker, R. F., Read, G. F., Wilson, D. W., Riad-Fahmy, D., \& Griffiths, K. (1990). Chronobiology in laboratory medicine: Principles and clinical applications illustrated from measurements of neutral steroids in saliva. Progress in Clinical Biological Research, 341A, 105-117.

Wallace, G. L., Dankner, N., Kenworthy, L., Giedd, J. N., \& Martin, A. (2010). Age-related temporal and parietal cortical thinning in autism-spectrum disorders. Brain, 133, 3745-3754.

Wallace, G. L., Eric, S. J., Lenroot, R., Viding, E., Ordaz, S., Rosenthal, M. A., Molloy, E. A., Clasen, L. S., Kendler, K. S., Neale, M. C., \& Giedd, J. N. (2006). A pediatric twin study of brain morphometry. Journal of Child Psychology and Psychiatry, 47, 987-993.
Wechsler, D., Kort, W., Compaan, E. L., Belichrodt, N., Resing, W. C. M., Schittekatte, M., Bosmans, M., Vermeir, G., \& Verhaeghe, P. (2002). Handleiding WISC-III ${ }^{n l}$ [Manual WISC-III ${ }^{n l}$ ]. London: The Psychological Corporation Limited, Nederlands Insitiuut van Psychologen Dienstencentrum.

Yakovlev, P. I., \& Lecours, A. (1967). The myelogenetic cycles of regional maturation of the brain. In A. Minkowski (Ed.), Regional development of the brain in early life (pp. 3-70). Oxford: Blackwell.

Yoon, U., Fahim, C., Perusse, D., \& Evans, A. C. (2010). Lateralized genetic and environmental influences on human brain morphology of 8-year-old twins. Neuroimage, 53, 11171125 . 